\title{
Intelligent Digital Public Address System using Agent Based on Network
}

\author{
Jung-Sook $\mathrm{Kim}^{+}$ \\ ${ }^{\dagger}$ Dept. of Multimedia, Kimpo College
}

\begin{abstract}
In this paper, we developed a digital and integrated PA(Public Address) system with speech recognition and sensor connection based on IP with an ID using agent. It has facilities such as an external input, a microphone and a radio for a PA system and has speech recognition. If "fire" is spoken to the PA system then it can recognize the emergency situation and will broadcast information to the appropriate agency immediately. In addition to that, many sensors, such as temperature, humidity, and infrared, etc., can be connected to the PA system and can be integrated with the context awareness which contains many types of information about internal statuses using inference agent. Also, developed the digital integrated PA system will make it possible to broadcast the message to adaptable places using network IP based on IDs. Finally, the digital PA system is designed for operation from a PC, which makes installation and setting of operating parameters very simple and user-friendly. For implementation details, we implemented thread based concurrent processing for the events which occur concurrently from many sensors or users.
\end{abstract}

Key Words : Intelligent Digital Public Address System, Speech Recognition, Sensor Connection, Context Awareness, Agent, Thread

\section{Introduction}

Simple PA systems are often used in small venues such as school auditoriums, churches, and small bars. PA systems with a large number of speakers are widely used in institutional and commercial buildings, to read announcements or declare states of emergency. Intercom systems, which are often used in schools, also have microphones in each room so that the occupants can reply to the central office. Sound reinforcement systems and PA systems may use some similar components, but with differing applications. Sound reinforcement systems are for live music or performance, where PA systems are for reproduction of speech and recorded music in buildings and institutions. There are two kinds of PA systems, which are an analog PA system and a digital PA system. The digital PA system has more communication quality than the analog PA, and it can operate multiple functions concurrently. There are a va-

접수일자: 2013년 1월 4일

심사(수정)일자: 2013년 2월 4일

게재확정일자 : 2013년 2월 5일

† Corresponding author

본 논문은 2012년도 김포대학교 연구비 지원에 의해 연구하였

음.

This is an Open-Access article distributed under the terms of the Creative Commons Attribution Non-Commercial License (http://creativecommons.org/licenses/by-nc/3.0) which permits unrestricted non-commercial use, distribution, and reproduction in any medium, provided the original work is properly cited riety of digital PA systems made by many companies. A Digital PA system is utilized in all public places attended by vast crowds of people. In daily operation, such systems are not only used for public information or for promotional advertising, but also for musical entertainment or for internal purposes like the communication among staff in widespread buildings (by live announcements or by intercom operation). In cases of emergency, such systems become particularly important: reliable alarming and acoustical guidance of crowds with people being directed to certain targets is absolutely necessary for the prevention of chaos and panic, so that organization of a scheduled evacuation can proceed as planned. Public address system over IP refers to PA paging and intercom systems that use an Ethernet or GSM-R network instead of a centralized amplifier to distribute the audio signal to all paging in a building or campus. Network-attached amplifiers and intercom units are used to provide the communication function. At the transmission end, a computer application transmits a digital audio stream via the local area network, using audio from the computer's sound card inputs or from stored audio recordings. At the receiving end, specialized intercom modules (sometimes known as IP speakers) receive these network transmissions and reproduce the analog audio signal. These are small specialized network appliances addressable by an IP address just like any other computer on the network. Such systems are inter-connected by networking and thus allow transmission to remote locations across the Internet or to a local area or campus network. It is also 
possible to provide for multiple stations for transmission control on such a network [1, 2]. However, PA system broadcast all offices or rooms which are connected them at a time nowadays. And if some users should not want to receive the sound then that is just noise. At this point, the PA would better to have a facility which is individually broadcasting function. In other words, if the PA must be broadcast the room number 1 , then the other rooms of connected PA except room number 1 doesn't operate the sound of the PA. These days, new buildings have an Intelligent Building System (IBS) facility which controls the buildings efficiently and easily. The IBS is connected many and various sensors which are temperature, humidity and infrared. Notably, the Korean government has strengthened the Fire Services Act of 2010 and most buildings must have a PA system facility in case of an emergency or announcement. Also, the number of senior citizens is increasing dramatically in the rural areas of Korea. Most of them live alone, isolated from the welfare system, security office, and police station, etc. If they face an emergency, such as a fire, gas explosion, natural disasters or health problem, etc., they typically call a next door neighbor, nearby policy station or their children. That can be a very difficult and complex process. First of all, they need to remember the telephone number or the touch key button, and push the key pads on the telephone. And, they might not have a lot of time. Also, they shouldn't have to go through the stress of it. At such a time, senior citizens need an easy and simple notification method. In this paper, we developed an intelligent digital and integrated PA system with speech recognition and sensor connection based on IP with an ID using agent. It has facilities such as an external input, a microphone, CD player, and a radio for a PA system and has speech recognition. If "fire" is spoken to the PA system in case of fire then it can recognize the emergency situation and will broadcast information to the appropriate agency immediately. In addition to that, many sensors, such as temperature, humidity, and infrared, etc., can be connected to the PA system and can be integrated with the context awareness which contains many types of information about internal statuses using agent [3, 4, 5, 6]. For example, if the humidity sensor sends information that humidity is high, then the PA system can intelligently unicast an adaptable response using agent, such as the following: 'turn off a heater', or 'open a window', at a certain place, through a network based on IP with an ID. Finally, the digital PA system is designed for operation from a PC, which makes installation and setting of operating parameters very simple and user-friendly. For implementation details, we implemented thread based concurrent processing for the events which occur concurrently from many sensors of devices or users. The structure of this paper is the following: Section 2 briefly introduces the related works.
Section 3 describes the intelligent digital integrated PA system, and section 4 presents the implementation details of the digital integrated PA system. Finally, conclusions are drawn and future work is discussed in section 5 .

\section{Related Works}

\subsection{Praesideo(Digital Public Address and Emergency Sound System)}

Praesideo[7] is a fully digital public address system that meets all the requirements placed by professional users on a public address/emergency system. The system brings highly innovative and advanced digital technology to the public address market. The processing and communication of both audio signals and control data entirely in the digital domain makes the system superior to other currently available public address and emergency sound systems. Digital signal processing allows significant improvements in the audio quality achieved. The Praesideo system is designed for configuration from a PC, which makes installation and setting of $\mathrm{op}^{-}$ erating parameters very simple and user-friendly. All audio processing is performed in the digital domain. Communication between the units is via plastic fiber or glass fiber cabling, depending on the distance between the units. The cabling uses the daisy chain principle. This makes the cabling and installation very quick, simple and easy. The system cabling is a closed loop, which allows redundancy to be achieved. The system is supplied with user-friendly software for system configuration. This allows all system functions to be configured. The software is based on web technology, which gives authorized users full freedom of configuration in terms of time and location. The simplified and accurate organization of the programming features makes navigation highly user-friendly and fault-tolerant. The software also provides clear indication of any parameters, which have not been programmed before exiting from any stage of the configuration process. The system architecture is based on daisy-chaining the units. It is possible to add or remove equipment anywhere in the network without affecting the performance of other units, provided that a network connection is available. This makes the system easily expandable by the customer, without adding any additional electronics at the network controller unit. Thanks to this network architecture, users can start with a small system in the initial stage and expand the system later simply by adding the required new units to the existing network. The system can also be configured for redundant cabling using a ring cabling structure.

\subsection{Agent}

Agents, special types of software applications, have be- 
come a very popular paradigm in computing in recent years. Some of the reasons for this popularity is their flexibility, modularity and general applicability to a wide range of problems. Recent increase in agent-based applications is also because of the technological developments in distributed computing, robotics and the emergence of object-oriented programming paradigms. Advances in distributed computing technologies has given rise to use of agents that can model distributed problem solving. Besides, object-oriented programming paradigm introduced important concepts into software development process which are used in structuring agent-based approaches. With the explosive growth of information sources available on the Internet, and on the business, government, and scientific databases, it has become increasingly necessary for users to utilize automated and intelligent tools to find the desired information resources, and to track, analyze, summarize, and extract "knowledge" from them. These factors have given rise to the necessity of creating server-side and client-side intelligent systems that can effectively mine for knowledge. Therefore, the inherent parallelism and complexity of the classification and discovering patterns from large amounts of data can be delegated to intelligent software agents. Agents are defined as software or hardware entities that perform some set of tasks on behalf of users with some degree of autonomy. In order to work for somebody as an assistant, an agent has to include a certain amount of intelligence, which is the ability to choose among various courses of action, plan, communicate, adapt to changes in the environment, and learn from experience. In general, an intelligent agent can be described as consisting of a sensing element that can receive events, a recognizer or classifier that determines which event occurred, a set of logic ranging from hard-coded programs to rule-based inferencing, and a mechanism for taking action.

\section{Intelligent Digital Public Address System}

\subsection{System Functions}

Figure 1 shows the digital integrated PA system structure. The digital PA system range of equipment has multiple functions combined in a single unit. This feature drastically reduces the number of different types of equipment used in the system. This makes the overall system highly cost-effective.

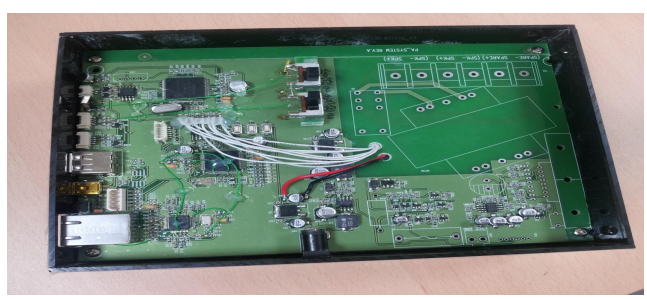

Fig. 1. System structure
As you can see in figure 1, it is composed of many functions which are speech recognition and sensor connection. The brief description of the features and role of each function is as follows:

\subsection{Agent for the Context Awareness}

An intelligent agent can be described as consisting of a sensing element that can receive events, a recognizer or classifier that determines which event occurred, a set of logic ranging from hard-coded programs to rule-based inferencing, and a mechanism for taking action.

Developed the PA system of this paper can broadcast prediction or periodical message because it uses a database system on a PC. It could search the information from the database to predict certain situation according to seasons or time, etc. The information is not obtained from sensors directly. It is made by the database which is composed of many fields using inference agent. For example, if the humidity sensor sends information that humidity is high, then the PA system can intelligently unicast an adaptable response, such as the following: 'turn off a heater', or 'open a window', at a certain place, through a network based on IP with an ID using agent. Also, the PA system could broadcast the periodical message for comfortable lifetime in offices or rooms of a building

\subsection{Design of an ID}

The ID object is used to identify object. It can be $\mathrm{ex}^{-}$ pressed in hierarchical structure with its Hierarchy property. Also it can be used duplicately with its Unique property. It basically uses a string of mixed characters and integers. The hierarchical structure is expressed by the literals "@" and ".". The literal "@” distinguishes device and where device is. The literal "." represents the hierarchical structure of the device itself or the location. The schema definition for the $\mathrm{ID}$ is as follows: <element name="User $\mathrm{ID}^{\prime \prime}$ type=" $\mathrm{ID}^{\prime \prime}$ Hierarchy $=$ "false" Unique $=$ "True" $/>, \quad<$ element name $=$ "DeviceII" type $=" \mathrm{ID}^{\prime \prime} \quad$ Hierarchy="true" Unique $=$ "false" $/>$ and the usage example is as follows: $<$ UserID $>$ Hong Gil Dong $</$ UserID $>$ $<$ DeviceID $>$ Monitor123.MyCom@MyOffice</DeviceID $>$

\subsection{Speech Recognition and Sensor Connection}

This PA system can provide context awareness of various events occurring in a building or a house. Also, it is able to recognize both speech and sounds, such as a fire bell and disaster bell, which signal to escape in emergency situations, and it can sense information which is sent from various sensors. If "fire" is spoken to the PA system in case of fire by someone then it can recognize the emergency situation and will broadcast information to the appropriate agency immediately. The following Table 1 shows the lists which are status values and commands for speech recognition of this PA 
system

Table 1. List of commands

\begin{tabular}{|l|l|l|}
\hline Status & Status Values & Commands \\
\hline Normal & Ox0 & Ox00(00) \\
\hline Fire & Ox1 & Ox0B(11) \\
\hline $\begin{array}{l}\text { High } \\
\text { Temperature }\end{array}$ & Ox2 & Ox016(22) \\
\hline $\begin{array}{l}\text { Low } \\
\text { Temperature }\end{array}$ & Ox3 & Ox21(33) \\
\hline Security Call & Ox4 & Ox2C(44) \\
\hline Help Call & Ox5 & Ox55(55) \\
\hline$\ldots$. & $\ldots$. & $\ldots$. \\
\hline
\end{tabular}

In addition to that, many sensors, such as temperature, humidity, and infrared, etc., can be connected to the PA system and can be integrated with the context awareness which contains many types of information about internal statuses. For example, if the humidity sensor sends information that humidity is high, then the PA system can intelligently unicast an adaptable response using agent, such as the following: 'turn off a heater', or 'open a window', at a certain place, through a network based on IP with an ID. Also, we designed the simple message format to transmit the data from a $\mathrm{PC}$ to a digital device and from a digital device to a PC in order to provide efficient information transmission. The transmission data unit in the PA is a byte and the maximum of each transmission is up to 8 bytes. In that way, we defined the $n$-bytes message format. Table 1 shows the message format. The first byte is the server identification to identify the devices. The sensor position field is 1 byte for identifying the sensors positions and the following byte is the sensor ID in order to identify the sensors. The status information field is for describing the sensor status information, such as 'fire' is $0 \times 1$ and 'high temperature' is $0 \times 2$, etc. The command and detailed information field represents the kinds of commands and detailed information for event commands, such as '0x0B is a fire', and '0x21 is high temperature,' etc. The time field is 4 bytes to store the event time into a database for retrieving information in case of an emergency.

Table 2. Message Format

\begin{tabular}{|l|l|}
\hline Field name & Size (byte) \\
\hline Server ID & 1 \\
\hline Sensor Position & 1 \\
\hline Sensor ID & 1 \\
\hline Status Information & 0.5 \\
\hline Command and Detailed Information & 0.5 \\
\hline Time & 4 \\
\hline
\end{tabular}

\subsection{Design of a DataBase Schema}

To save a lot of sensor or event information, we developed a database for the digital PA system. The fol- lowing figure 2 , shows a database schema which has six entities: room, user, temperature, infrared, smoke, and emergency entities.

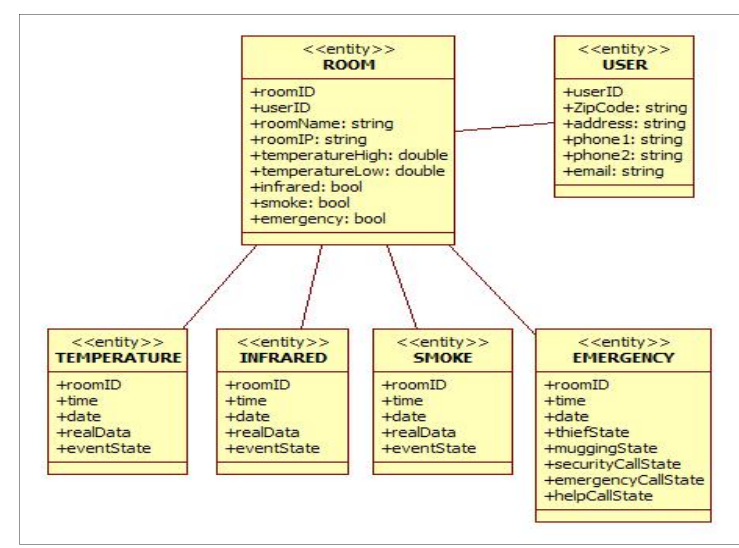

Fig. 2. DB schema

\subsection{Parallel Event Processing}

The proposed PA system connects a lot of sensors of devices, and clients and the events can occur concurrently. So, it must have a parallel processing method. In this paper, a thread was used to process the parallel events. Threads were created in the same number as events to service the events concurrently as they happen. At this point, the system performance must be considered, and synchronization is an important factor as well. Depending on the system's performance, a fixed number of threads is created and services are processed by each thread.

\section{Implementation and Results}

We have implemented an intelligent and digital PA system with the design presented in the previous $\mathrm{sec}^{-}$ tion using $\mathrm{C}$ and $\mathrm{C \#}$ language on Windows. The system is supplied with user-friendly software for system operation. The software is based on Windows, which gives users easy and simple use of operation. For speech recognition, we use the $\mathrm{RSC}-4128$ [8] processor which represents Sensory's next generation speech and analog I/O mixed signal processor. The RSC-4128 is designed to bring advanced speech I/O features to cost sensitive embedded and consumer products. Based on an 8-bit microcontroller, the RSC-4128 integrates speech-optimized digital and analog processing blocks into a single chip solution capable of accurate speech recognition; high quality, low data-rate compressed speech; and advanced music [8]. And the Microchip PIC32MX5XX family was used for Ethernet [9]. In order to communicate between user and PA system, socket programming method was used based on TCP/IP. As you can see in figure 3, if "fire" is spoken 
to the microphone of the PA system then the processor recognizes the status and translates the voice into "Ox1" code. After that, the code is transmitted to the server so the server sends a broadcast message to the officers and residents or it calls emergency call to the fire station immediately. In main menu of the system, if the system status is normal then all window dialog colors are green, but it recognizes the voice then the window dialog color changes green into red.

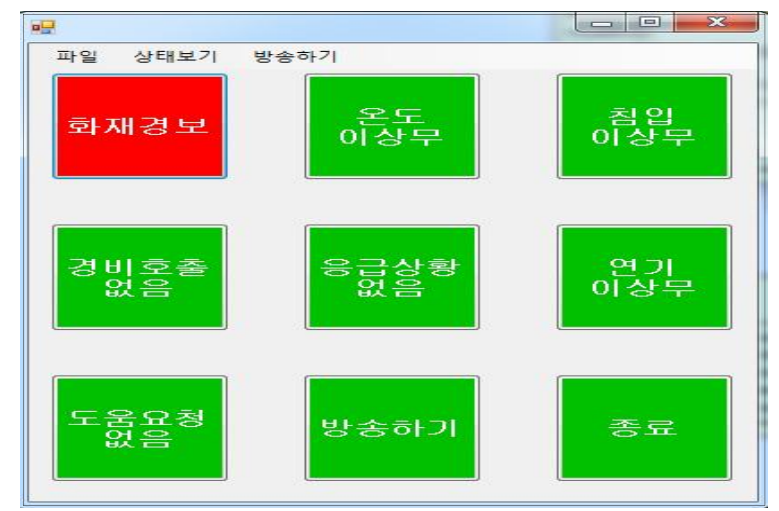

Fig. 3. Fire

The following figure 4 shows the fire emergency situation. If the intelligent digital PA recognizes the fire, then it can call a fire station and a control center to inform the fire. Also, it must broadcast escape message for the officers or residents. After that it sends a message which says that your office or your house is firing.

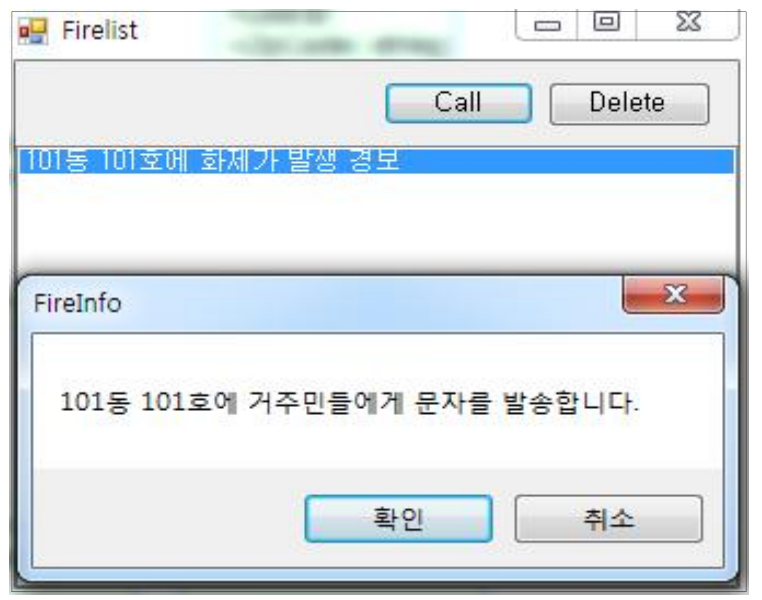

Fig. 4. Fire call

The following figure 5 shows the result of context awareness using agent. The dialog says that the one place is high temperature and that place must control the heater in order to keep the normal temperature. Also, that place has faced a lot of possibility of fire emergency and the one place should check the internal status.

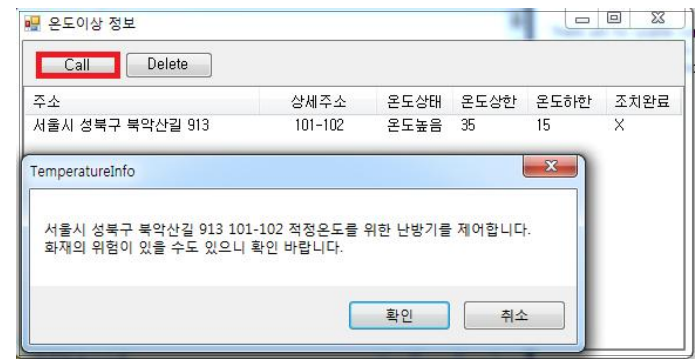

Fig. 5. Context awareness

The figure 6 shows the number of occurrences of fire emergency at the one place per 3-month. The fire condition depends on the seasons and various parameters. As the results, our system shows the number of occurrences of occurred fire emergency per each season. That result made from database in real-time.

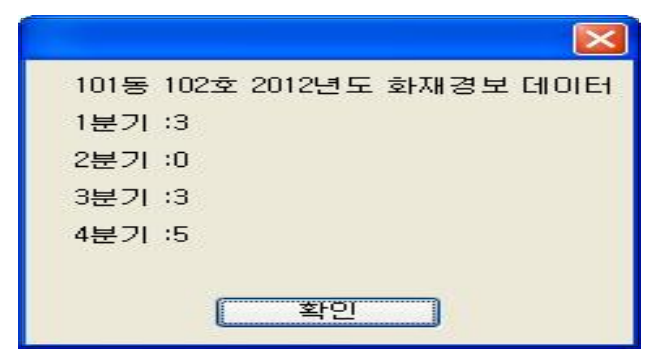

Fig. 6. The number of occurrences of fire emergence

As you can see in figure 6, the intelligent digital PA system can sense information which is sent from various sensors. For example, if the humidity sensor sends information that humidity is high, then the PA system can intelligently unicast an adaptable response, such as the following: 'turn off a heater', or 'open a window', at a certain place, through a network based on IP with an ID. Figure 7 shows the status information list of the various sensors which are smoke, infrared, and temperature, etc.

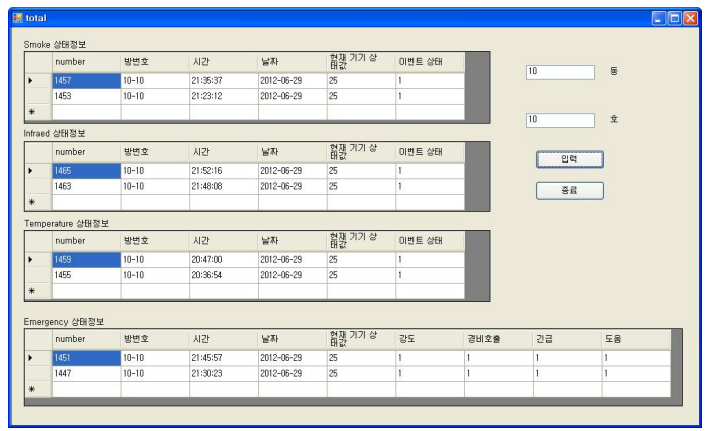

Fig. 7. List of sensors status information

In Table 3, we compared the results between Praesideo and the proposed PA system. As you can see in it, our system is more intelligent PA system than Praesideo. Also it is more convenient than Praesideo for senior 
citizen in case of emergency because of speech recognition. It does not need the call or any machine operation to inform the situation immediately to a police station or a social security office.

Table 3. Comparison of the results

\begin{tabular}{|l|c|c|}
\hline Features & Praesideo & Proposed PA \\
\hline $\begin{array}{l}\text { Speech } \\
\text { Recognition }\end{array}$ & $\mathrm{X}$ & $\mathrm{O}$ \\
\hline $\begin{array}{l}\text { Sensor } \\
\text { Connection }\end{array}$ & $\mathrm{X}$ & $\mathrm{O}$ \\
\hline $\begin{array}{l}\text { Context } \\
\text { Awareness }\end{array}$ & $\mathrm{X}$ & $\mathrm{O}$ \\
\hline Network & $\mathrm{O}$ & $\mathrm{O}$ \\
\hline PC-based & $\mathrm{O}$ & $\mathrm{O}$ \\
\hline
\end{tabular}

\section{Conclusions and Future Works}

In this paper, we developed an intelligent digital, minimized and integrated PA system with speech recognition and sensor connection based on IP with an ID. It has facilities such as an external input, a microphone, $\mathrm{CD}$ player, and a radio for a PA system and has speech recognition. If "fire" is spoken to the PA system then it can recognize the emergency situation and will broadcast information to the appropriate agency immediately. In addition to that, many sensors, such as temperature, humidity, and infrared, etc., can be connected to the PA system and can be integrated with the context awareness which contains many types of information about internal statuses using agent. Also, developed the digital integrated PA system will make it possible to broadcast the message to adaptable places using network IP based on IDs. Finally, the digital PA system is designed for operation from a PC, which makes installation and setting of operating parameters very simple and user-friendly. In this paper, a thread was used to process the parallel events. Threads were created in the same number as events to service the events concurrently as they happen. In the future work, we will extend the digital PA system that has one more function. That function operates like this: if you are in darkness of emergency, then you can move according to an escape path, listening a sound.

\section{References}

[1] From Wikipedia, the free encyclopedia, Public Address, http://en.wikipedia.org/wiki/Public_address, 2012.

[2] J. S. Kim, C. W. Song, "Development of Integrated Public Address System for Intelligent Building", Journal of Korean Institute of intelligent Systems, Vol. 21, No. 2, pp. 212-217, 2011.

[3] G. H. Lee, W. G. Kim, "Robust Speech Parameters for the Emotional Speech Recognition”, Journal of Korean Institute of intelligent Systems, Vol. 22, No. 6, pp. 681-686, 2012.

[4] H. S. Nwana, M. Wooldridge, "Software Agent Technologies", Software Agents and Soft Computing: Towards Enhanced Machine Intelligence, Lecture Notes in Artificial Intellignece 1198, pp. 59-77, 1997.

[5] S. Russell, P. Norvig, Artificial Intelligence: A modern Approach, Prentice-Hall, 1995.

[6] R. Murch, T. Johnson, Intelligent Software Agents, Prentice-Hall, 1999.

[7] Bosch security systems worldwide, "Praesideo Digital Public Address and Emergency Sound System", http://www. boschsecurity.com, 2012.

[8] Sensory Inc., RSC-4128 Speech Recognition Processor.

[9] Microchip Technology Inc., PIC32MX5XX/6XX/7XX Family Data Sheet

\section{저 자 소 개}

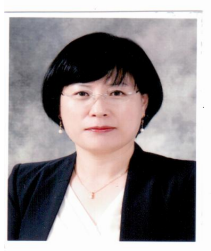

김정숙(Jung-Sook Kim)

1993년 : 동국대학교 컴퓨터공학과 공학사

1995년 : 동국대학교 대학원 컴퓨터공학과 공학석사

1999년 : 동국대학교 대학원 컴퓨터공학과 공학박사

2000년 현재 : 김포대학교 IT학부 멀티미 디어과 교수

2010년 현재 : 한국지능시스템학회 이사

관심분야 : IT 융합, 인공 지능, 유전 및 진화 알고리즘

Phone : +82-31-999-4659

E-mail : kimjs@kimpo.ac.kr 